\title{
In Situ Activation of an Indium(III) Triazenide Precursor for Epitaxial Growth of Indium Nitride by Atomic Layer Deposition
}

Nathan J. O’Brien,* Polla Rouf, Rouzbeh Samii, Karl Rönnby, Sydney C. Buttera, Chih-Wei Hsu, Ivan G. Ivanov, Vadim Kessler, Lars Ojamäe, and Henrik Pedersen

Cite This: Chem. Mater. 2020, 32, 4481-4489

Read Online

ABSTRACT: Indium nitride ( $\mathrm{InN}$ ) is characterized by its high electron mobility, making it a ground-breaking material for high frequency electronics. The difficulty of depositing high-quality crystalline InN currently impedes its broad implementation in electronic devices. Herein, we report a new highly volatile In(III) triazenide precursor and demonstrate its ability to deposit high-quality epitaxial hexagonal InN by atomic layer deposition (ALD). The

$$
[\mathrm{Pr}-\mathrm{N}
$$
new In(III) precursor, the first example of a homoleptic triazenide used in a vapor deposition process, was easily synthesized and purified by sublimation. Thermogravimetric analysis showed single step volatilization with an onset temperature of $145{ }^{\circ} \mathrm{C}$ and negligible residual mass. Strikingly, two temperature intervals with selflimiting growth were observed when depositing InN films. In the high-temperature interval, the precursor underwent a gas-phase thermal decomposition inside the ALD reaction chamber to produce a more reactive $\mathrm{In}$ (III) compound while retaining self-limiting growth behavior. Density functional theory calculations revealed a unique two-step decomposition process, which liberates three molecules of each propene and $\mathrm{N}_{2}$ to give a smaller tricoordinated In(III) species. Stoichiometric InN films with very low levels of impurities were grown epitaxially on $4 \mathrm{H}-\mathrm{SiC}$. The $\mathrm{InN}$ films deposited at $325{ }^{\circ} \mathrm{C}$ had a sheet resistivity of $920 \Omega /$ sq. This new triazenide precursor enables ALD of InN for semiconductor applications and provides a new family of $\mathrm{M}-\mathrm{N}$ bonded precursors for future deposition processes.

\section{INTRODUCTION}

The high electron mobility of indium nitride $(\operatorname{InN})^{1,2}$ makes it a very interesting material for the conduction channel in high electron mobility transistors (HEMTs) and high frequency electronics. InN can be integrated in state-of-the-art electronic devices that are based on aluminum- and gallium nitride (AlN and $\mathrm{GaN}$ ) and their alloys, given the close similarities in their crystal lattices. The implementation of $\mathrm{InN}$ into device structures requires deposition of epitaxially orientated and stoichiometric InN thin films with negligible impurities on substrates with high thermal conductivity such as $\mathrm{SiC} .^{3}$ The current chemical vapor deposition (CVD) processes used for depositing thin films of $\mathrm{AlN}$ and $\mathrm{GaN}$, at high temperatures of 800-1000 ${ }^{\circ} \mathrm{C}$, are not suitable for depositing $\mathrm{InN}$ as it decomposes to In metal and $\mathrm{N}_{2}$ gas at approximately $500{ }^{\circ} \mathrm{C}$. ${ }^{4}$ This sets a strict upper temperature limit for CVD of $\mathrm{InN}$ where the reactivity of the nitrogen precursor, ammonia $\left(\mathrm{NH}_{3}\right)$, is very low, forcing $\mathrm{N} / \mathrm{In}$ ratios in the order of $10^{5}$ and thus poorly functioning CVD chemistry. ${ }^{5,6}$ Atomic layer deposition (ALD) is a low temperature time-resolved form of CVD, in which the metal and nonmetal precursors are pulsed into the reaction chamber sequentially. This process allows for the deposition of the resulting film to be governed solely by surface chemical reactions. ${ }^{7}$ The ALD cycle is repeated hundreds of times to deposit films with controlled thickness, excellent large-area uniformity, and conformity. We envision that ALD is the way forward to realize electronics based on InN. Although ALD is routinely used in the production of modern electronic devices, its potential for InN is yet to be unlocked. This is mostly due to the poor deposition chemistry afforded at low temperatures by the commonly used trimethylindium $\left(\mathrm{InMe}_{3}\right)$ precursor. ALD of InN with $\mathrm{InMe}_{3}$ and either $\mathrm{N}_{2}{ }^{8,9}$ or $\mathrm{NH}_{3}{ }^{10}$ plasma has produced epitaxial InN on $\mathrm{GaN}(0001), \mathrm{Si}(111)$, and sapphire substrates ${ }^{8,11,12}$ but renders films with high carbon and oxygen impurity levels and nonstoichiometric In/ $\mathrm{N}$ ratios.

For successful ALD, it is important to have a metal precursor with high volatility and thermal stability that cleanly reacts with the surface to avoid unwanted byproducts. ${ }^{7}$ Efforts have been made to develop In(III) precursors with favorable surface chemistry for ALD of InN by replacing the $\mathrm{M}-\mathrm{C}$ bonds of $\mathrm{InMe}_{3}$ with $\mathrm{M}-\mathrm{N}$ bonds. Homoleptic tricoordinated $\mathrm{M}-\mathrm{N}$ bonded compounds have been reported, ${ }^{13-17}$ but these often require bulky ligands to stabilize the In center, which reduces their volatility. Instead, homoleptic hexacoordinated $\mathrm{M}-\mathrm{N}$

Received: December 14, 2019

Revised: April 24, 2020

Published: April 24, 2020 
Scheme 1. Synthesis of Tris(1,3-diisopropyltriazenide)indium(III) 1.

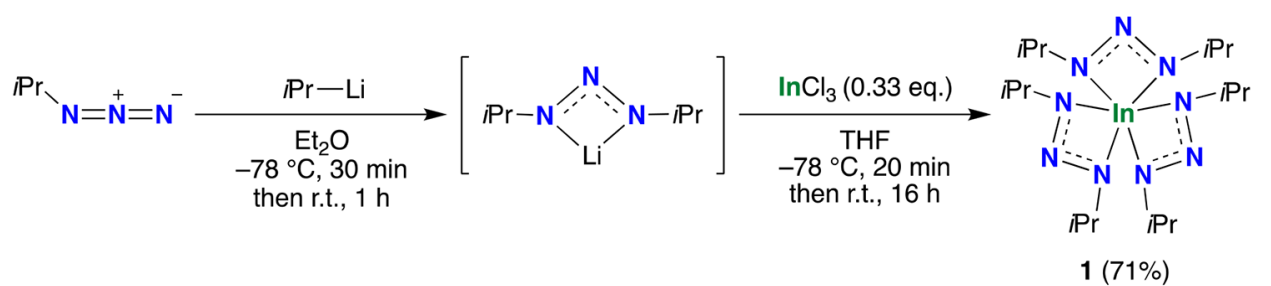

bonded precursors, $\operatorname{In}(\mathrm{III})$ tris-amidinate $\left(\operatorname{In}(\mathrm{amd})_{3}\right){ }^{18}$ formamidinate $\left(\operatorname{In}(\mathrm{famd})_{3}\right),{ }^{19}$ and guanidinate (In(guan $\left.)_{3}\right)^{20,21}$ have shown increased thermal stability in comparison to tricoordinated $\mathrm{In}$ (III) precursors and were first used for ALD of $\operatorname{In}_{2} \mathrm{O}_{3}{ }^{19,21}$ and $\mathrm{In}_{2} \mathrm{~S}_{3}{ }^{22}$. Recently, we investigated these precursors with $\mathrm{NH}_{3}$ plasma for ALD of crystalline $\mathrm{InN}^{23}$ The best results were achieved with In (famd $)_{3}$, giving the highest degree of crystallinity, lowest impurity levels, and an $\mathrm{In} / \mathrm{N}$ ratio of 1.01 . It was further revealed that smaller and less electron donating substituents on the endocyclic carbon of the amidinate ligand backbone led to an improved surface chemistry in ALD of InN films. To further explore this trend, we envisaged changing the endocyclic position to an even smaller and more electron-withdrawing moiety. A ligand that is closely related to the amidinates is the triazenide, which differs only by the electronegative nitrogen atom in the endocyclic position of the ligand backbone. Although the binding modes of amidinates are similar to those of triazenides, the extra nitrogen atom is thought to make the chelating nitrogens weaker binders. ${ }^{24,25}$ This would benefit the surface reactions of the precursor during deposition by making the In-N bonds weaker and the In metal center more electrophilic. There are many examples of homoleptic triazenide complexes in the literature, ${ }^{25-34}$ including an In(III) complex $\left(\operatorname{In}(\text { dptriaz })_{3}\right) ;^{35,36}$ however, these are undesirable for vapor deposition due to the 1,3-diphenyltriazenide ligand. Homoleptic 1,3-dimethyltriazenide ${ }^{37}$ and heteroleptic 1-tertbutyl-3-alkyltriazenide ${ }^{38,39}$ complexes have also been reported for various metals, but these suffer from low volatility and thermal stability. To the best of our knowledge, there are no examples of a homoleptic 1,3-dialkyltriazenide complex used for vapor deposition. Herein, we report the synthesis, structure, and physical properties of a new In(III) precursor, tris(1,3diisopropyltriazenide)indium(III) $\mathbf{1}$, and demonstrate it as an excellent ALD precursor for epitaxial $\mathrm{InN}$ thin films on $4 \mathrm{H}$ $\mathrm{SiC}$.

\section{RESULTS AND DISCUSSION}

2.1. Synthesis and Characterization of In(III) Triazenide Precursor. Reaction of isopropylazide ${ }^{40}$ with isopropyllithium generated the lithium 1,3-diisopropyltriazenide intermediate, which was reacted directly with indium trichloride $\left(\mathrm{InCl}_{3}\right)$ at $-78{ }^{\circ} \mathrm{C}$ to give tris(1,3-diisopropyltriazenide)indium(III) $\mathbf{1}$ in a $71 \%$ yield (Scheme 1 ). Compound $\mathbf{1}$ was isolated as a colorless solid after purification by sublimation. It was found to be highly stable at room temperature in both solid and solution states under an inert atmosphere; however, exposure to air led to decomposition to a white insoluble powder thought to be of $\operatorname{In}_{2} \mathrm{O}_{3}$. The compound was characterized by nuclear magnetic resonance (NMR) spectroscopy, mass spectrometry (MS), elemental analysis, and X-ray crystallography.
The crystal structure of $\mathbf{1}$ (Figure 1, Tables S1-S5) showed the In atom in a distorted-octahedral coordination geometry

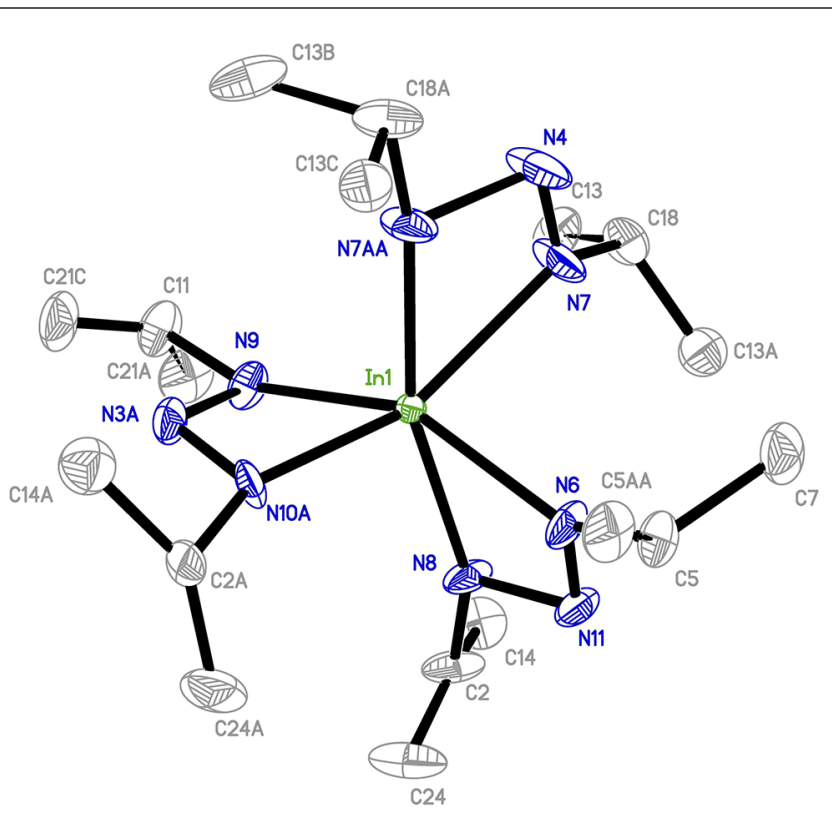

Figure 1. ORTEP drawing of 1 with thermal ellipsoids at the 50\% probability level. All hydrogen atoms were removed for clarity.

with the triazenide ligands in a pseudo- $C_{3}$ propeller arrangement similarly to the previously reported In(dptriaz) $)_{3}{ }^{36}$ Two of the ligands were found to be distorted over four positions and the third over two positions. The In $-\mathrm{N}$ bond lengths (av. 2.21(5) $\AA$ ) were similar to that of $\operatorname{In}(\text { dptriaz) })_{3}$ (av. 2.237(6) $\AA),{ }^{36} \operatorname{In}(\text { famd })_{3}$ (av. 2.252(13) $\left.\AA\right),{ }^{19} \operatorname{In}(\text { amd })_{3}$ (av. 2.236(1) $\AA){ }^{18}$ and $\operatorname{In}(\text { guan })_{3}$ (av. 2.260(4) $\AA$ ), ${ }^{20,21}$ showing that the alkyl-triazenide ligand has little effect on the $\mathrm{In}-\mathrm{N}$ bond distances.

The ${ }^{1} \mathrm{H}$ NMR spectrum of 1 in $\mathrm{C}_{6} \mathrm{D}_{6}$ showed one septet at $4.06 \mathrm{ppm}$ and one doublet at $1.23 \mathrm{ppm}$ for the methine proton and methyl groups of the isopropyl moiety, respectively (Figure S1). This indicates that $\mathbf{1}$ exists as a monomer in solution state, which is also reflected in the solid-state structure. MS analysis gave a molecular ion at $500 \mathrm{~m} / z$, confirming its identity. Compound $\mathbf{1}$ was found to be highly volatile and sublimed at $80{ }^{\circ} \mathrm{C}(0.5 \mathrm{mbar})$ with no visible solid remaining. Thermogravimetric analysis (TGA) showed the new precursor volatilized completely in a single step from 145 to $215{ }^{\circ} \mathrm{C}$, with only $2 \%$ of residual mass (Figure 2 ). A thermal stress test with a higher mass loading of precursor showed a slight shift to a higher temperature $\left(160-235{ }^{\circ} \mathrm{C}\right)$ without signs of decomposition (Figure S3a). The 1 Torr vapor pressure of 1 was shown to occur at $134{ }^{\circ} \mathrm{C}$ (Figure S3b), and its $\Delta H$ of vaporization was $65.8 \mathrm{~kJ} \mathrm{~mol}^{-1}$ (Figure S3c). 


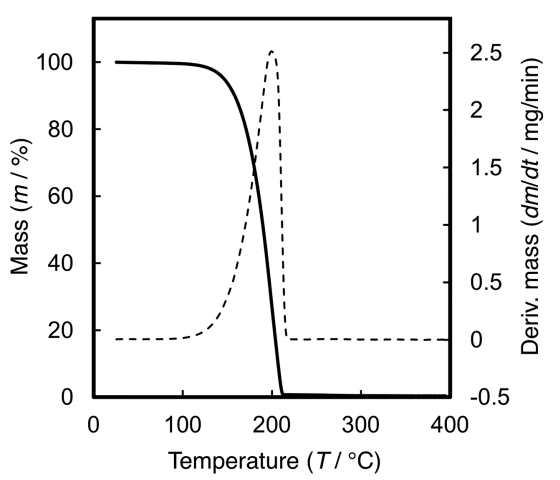

Figure 2. Thermogravimetric analysis of compound $\mathbf{1}$.

The heterolytic bond dissociation energy of the In-N bonds for 1 was calculated by density functional theory (DFT) to be $289 \mathrm{~kJ} \mathrm{~mol}^{-1}$, which is lower than that of $\operatorname{In}(\text { famd })_{3}(312 \mathrm{~kJ}$ $\mathrm{mol}^{-1}$ ) (Table S6) and indicates a slightly weaker In-N bond. The natural charges of the In $(+1.47)$ and $\mathrm{N}(-0.44)$ atoms of 1 show a less polarized $\mathrm{In}-\mathrm{N}$ bond character in comparison to the previously used $\operatorname{In}(\text { famd })_{3}(\mathrm{In},+1.78 ; \mathrm{N},-0.69)$ (Table S7). Both the HOMO $\pi$ and LUMO $\pi^{*}$ frontier orbitals of 1 are localized on the $\mathrm{N}_{3}$ moiety of the triazenide ligand (Figure $3 a, b)$. The high electron density on the backbone of the ligand a)
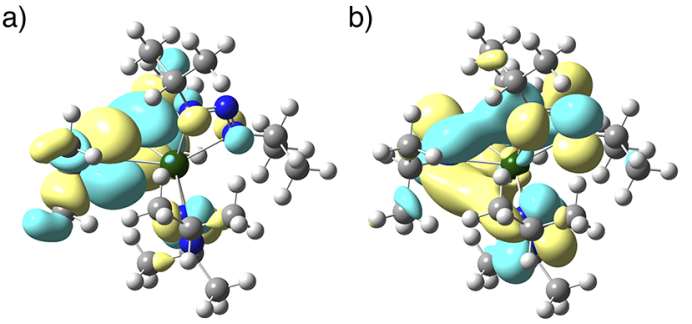

Figure 3. (a) HOMO (-5.90 eV) and (b) LUMO $(-0.69 \mathrm{eV})$ of 1 from DFT calculations.

could explain the increased volatility of $\mathbf{1}$ due to electrostatic repulsion forces in solid state. This is consistent with the crystal structure, which is highly disordered because of a lack of intermolecular interactions.

2.2. ALD of InN Using In(III) Triazenide Precursor. ALD of InN was tested initially on $\mathrm{Si}(100)$ using $5 \mathrm{~s}$ pulse of 1 and $9 \mathrm{~s} \mathrm{NH}_{3}$ plasma pulse, separated by a $9 \mathrm{~s} \mathrm{~N}_{2}$ purge, while varying the deposition temperature. These experiments revealed two temperature intervals where the growth per cycle (GPC) was constant with temperature, at $220-250{ }^{\circ} \mathrm{C}$ and $300-350{ }^{\circ} \mathrm{C}$ (Figure 4a). Saturation curves on $\mathrm{Si}(100)$ of the lower and higher temperature intervals showed saturation growth behavior with a GPC of $0.4 \AA$ /cycle and $1.2 \AA /$ cycle, respectively, after a $5 \mathrm{~s}$ pulse of 1 and $9 \mathrm{~s}$ pulse of $\mathrm{NH}_{3}$ plasma (Figure $4 b, c)$. These results indicate a self-limiting surface chemistry for $\mathbf{1}$ and $\mathrm{NH}_{3}$ plasma at both the lower and higher temperature regions. The high-temperature interval growth rate is three and four times that of our previous reports using $\mathrm{In}(\text { famd })_{3}(0.4 \AA / \text { cycle })^{23}$ and $\operatorname{InMe}_{3}(0.32 \AA / \text { cycle })^{10}$, respectively, with $\mathrm{NH}_{3}$ plasma.

Furthermore, the high-temperature interval indicates a higher thermal stability of the chemisorbed species in comparison to the previously used $\operatorname{In}(\text { famd })_{3}$, which has a constant GPC over a wide temperature range of 200-280
${ }^{\circ} \mathrm{C} .{ }^{23}$ A linear growth trend was observed when all the parameters were kept constant upon increasing ALD cycles at 220 and $300{ }^{\circ} \mathrm{C}$ (Figures S7 and 4d).

2.3. Thermal Properties of In(III) Triazenide Precursor. The presence of two temperature intervals with selflimiting growth is highly exceptional for ALD. Differential scanning calorimetry (DSC) analysis of 1 shows two exothermic events, a sharp peak between 150 and $180{ }^{\circ} \mathrm{C}$, and a broad peak between 220 and $280{ }^{\circ} \mathrm{C}$ (Figure S4). The onset temperature of the first exothermic event coincides with the onset volatilization temperature observed in the TGA $\left(\sim 145{ }^{\circ} \mathrm{C}\right)$, which could indicate decomposition and volatilization occurring simultaneously. Heating of $\mathbf{1}$ in solid state to $180^{\circ} \mathrm{C}$ for $16 \mathrm{~h}$ showed only slight discoloration of the sample with no signs of decomposition by ${ }^{1} \mathrm{H}$ NMR analysis. These results suggest that the first exothermic event does not correspond to a decomposition pathway. The spike in growth rate between 250 and $300{ }^{\circ} \mathrm{C}$ lines up with the second broad exothermic event between 220 and $280{ }^{\circ} \mathrm{C}$, which contains three overlapping peaks at approximately 245,255 , and 270 ${ }^{\circ} \mathrm{C}$. Heating studies of $\mathbf{1}$ in solid and solution states (Figure S5) above $200{ }^{\circ} \mathrm{C}$ confirmed this to be a decomposition event, giving In metal and an unidentifiable brown solid. This is a strong indication that $\mathbf{1}$ decomposes in the gas-phase inside the deposition chamber to a more volatile and reactive species at $\sim 250{ }^{\circ} \mathrm{C}$. It is worth pointing out that even though this is usually an unwanted ALD precursor property, in this case the decomposition product still retains self-limiting growth behavior.

The thermal decomposition of $\mathbf{1}$ was studied by DFT calculations at $300{ }^{\circ} \mathrm{C}$ showing two possible pathways (Figure $5 a)$. The first common step of both pathways is a transfer of a hydrogen from the methyl group of the isopropyl moiety to the endocyclic nitrogen, releasing a propene molecule to form A. Compound A can tautomerize through a hydrogen transfer to the exocyclic nitrogen to give $\mathbf{B}$. The other possible path, which is more energetically favored, is migration of the hydrogen onto the exocyclic tertiary nitrogen while simultaneously releasing $\mathrm{N}_{2}$ to form $C$. The free energies for the decomposition path are shown at $300{ }^{\circ} \mathrm{C}$ (Figure $5 \mathrm{~b}$ ). The energy for the final structure $\mathrm{C}\left(\Delta G^{\circ}=-245 \mathrm{~kJ} \mathrm{~mol}^{-1}\right)$ is much lower than 1 due to the large increase of entropy when releasing two molecules. This indicates that at higher temperature and lower pressure, structure $\mathbf{C}$ would be expected to dominate. Further calculations show that all three ligands decompose simultaneously via this pathway to give a tricoordinated In(III) species of C (Tables S10 and S11). Decomposition of the triazenide ligand of $\mathbf{1}$ is uniquely different to that of amidinates and guanidinates, which have been shown to thermally decompose by either carbodiimide deinsertion or $\beta$-hydrogen abstraction. ${ }^{41}$ This highlights the reduced hydride reactivity of the $\beta$-hydrogen on the isopropyl moiety by the electron-withdrawing triazenide ligand and removes the need for a bulky tert-butyl exocyclic substituent to block this position.

2.4. InN Film Characterization. The films deposited at both temperature intervals rendered polycrystalline hexagonal wurtzite InN on $\mathrm{Si}(100)$ (Figure S8a-c). Deposition on $4 \mathrm{H}$ $\mathrm{SiC}(0001)$, which has a smaller lattice mismatch with $\mathrm{InN},{ }^{3}$ at $325{ }^{\circ} \mathrm{C}$ with 5 s pulse of 1 and $9 \mathrm{~s} \mathrm{NH}_{3}$ plasma pulse rendered epitaxial wurtzite InN. The $\theta-2 \theta$ X-ray diffraction (XRD) measurement shows InN peaks corresponding to the (0002), (0004), and (0006) planes indicating growth along the $c$-axis 
a)

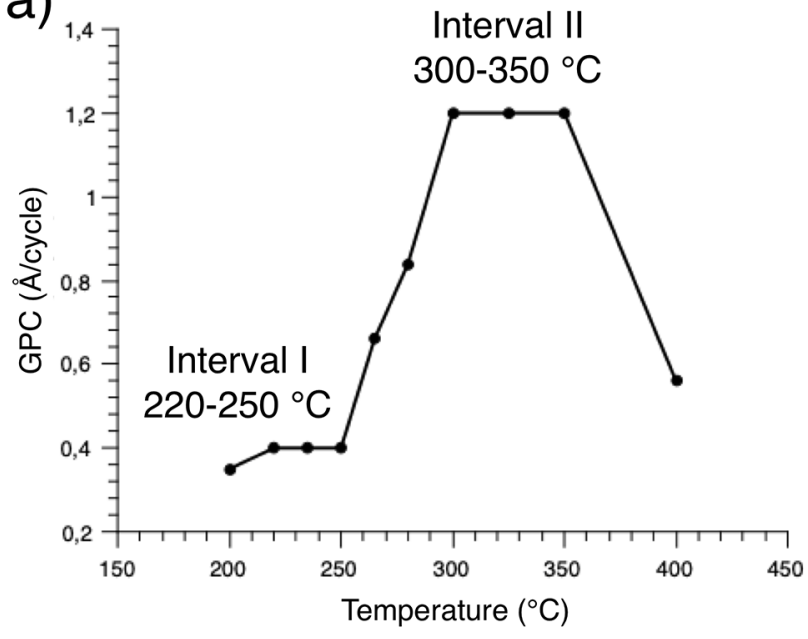

c)

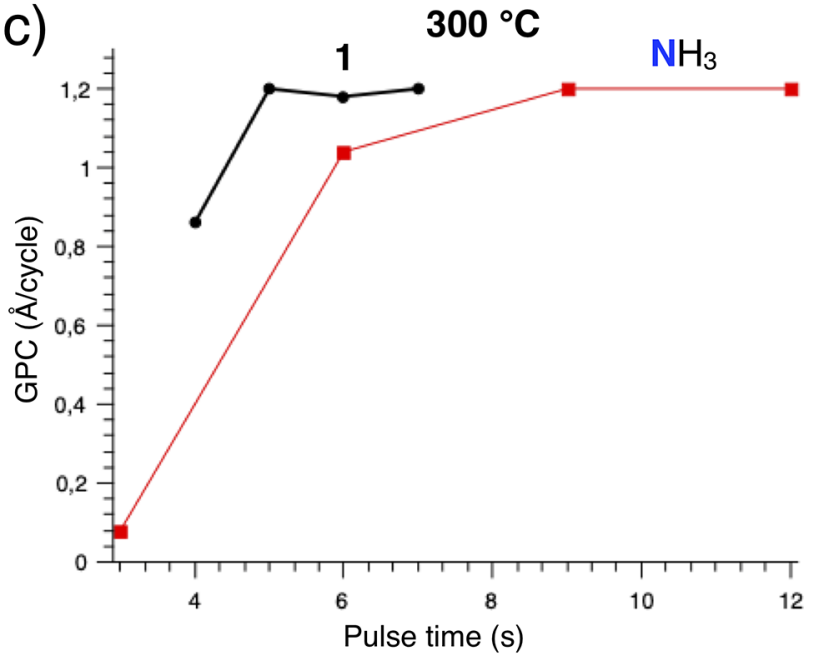

b)

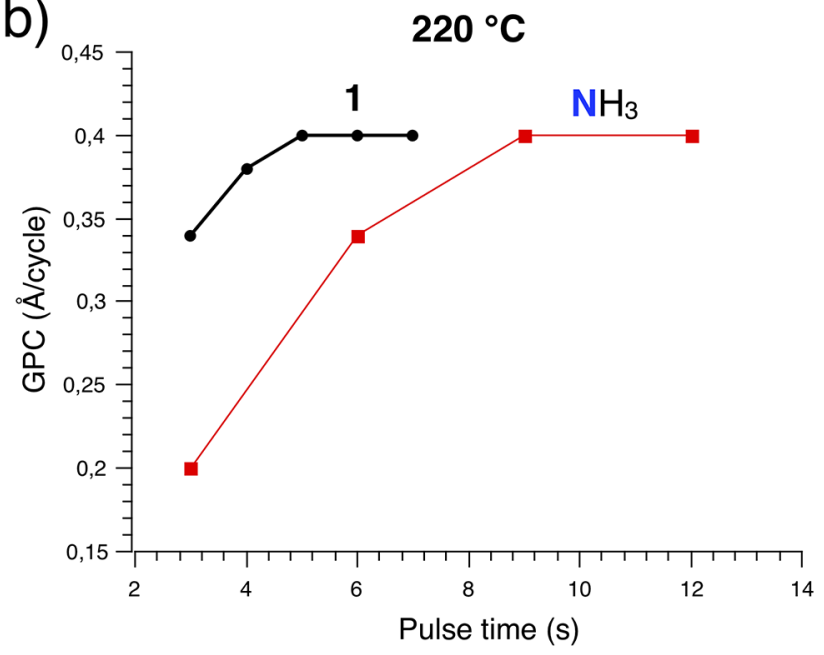

d)

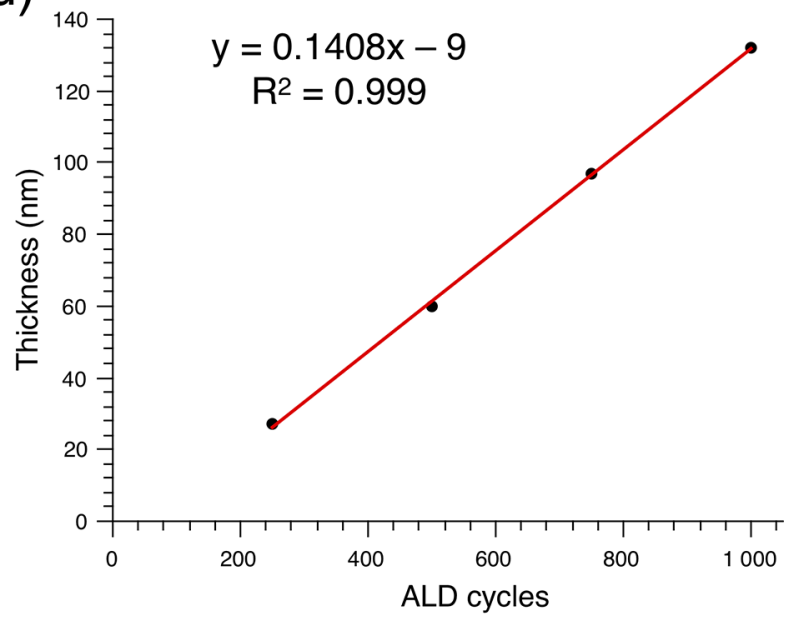

Figure 4. (a) Growth dependence on process temperature using a 5 s pulse of 1 and 9 s pulse of $\mathrm{NH}_{3}$ on $\mathrm{Si}(100)$. (b) Growth per cycle behavior of 1 and $\mathrm{NH}_{3}$ pulses deposited at $220{ }^{\circ} \mathrm{C}$ on $\mathrm{Si}(100)$. (c) Growth per cycle behavior of 1 and $\mathrm{NH}_{3}$ pulses deposited at $300{ }^{\circ} \mathrm{C}$ on $\mathrm{Si}(100)$. (d) Growth behavior of 1 at $300{ }^{\circ} \mathrm{C}$ dependent on the number of cycles using a $5 \mathrm{~s}$ pulse of $\mathbf{1}$ and a $9 \mathrm{~s} \mathrm{NH}_{3}$ plasma pulse on $\mathrm{Si}(100)$. The red line indicates the linear trend.

(Figure 6a). Grazing incidence XRD (GIXRD) shows no peaks, indicating no tilted grains (Figure $S 8 \mathrm{~d}$ ). XRD pole figures of the $\operatorname{InN}(10-11)$ and $(10-12)$ peaks were constructed to study the in-plane grain orientation and the crystal relationship between the film and the substrate (Figures S9 and $6 \mathrm{~b}$ ). Both pole figures show 12 poles, with 6 poles corresponding to $4 \mathrm{H}-\mathrm{SiC}(\mathrm{hkil})$ and 6 poles to the $\mathrm{InN}$ film. This is expected for an epitaxially grown hexagonal film on a hexagonal substrate due to its six-folded symmetry. Note that in the (10-11) plane (Figure S9), the poles for the substrate and the InN film overlap. A distinct difference between the substrate and the InN poles was observed for the $(10-12)$ plane (Figure $6 \mathrm{~b}$ ), where the inner 6 poles correspond to the InN film, and the outer 6 poles correspond to the $\mathrm{SiC}$ substrate.

The $\theta-2 \theta \mathrm{XRD}$, GIXRD, and pole figure measurements show that each $\mathrm{InN}$ hexagon grows epitaxially on a $\mathrm{SiC}$ hexagon, with in-plane relations $\mathrm{InN}[10-11] \| 4 \mathrm{H}-\mathrm{SiC}[10-11]$ and InN $[10-12] \| 4 \mathrm{H}-\mathrm{SiC}[10-12]$. This confirms the epitaxial relationship between the $\mathrm{InN}$ film and the $\mathrm{SiC}$ substrate along the $c$-axis; InN [0002] II 4H-SiC [0001].
A top-view scanning electron microscope (SEM) image of the InN films on $4 \mathrm{H}-\mathrm{SiC}$ shows homogeneously ordered grains along horizontal lines with a line width of approximately 130 $\mathrm{nm}$ (Figure 6c). This indicates that the InN films grow on the terrace of the $4 \mathrm{H}-\mathrm{SiC}$ substrate, leaving partially uncoated stepedges. ${ }^{42}$ We speculate that the step-edge acts as a surface diffusion barrier for the atoms, forcing them to nucleate at the step-edge, and the InN film starts to grow along the terrace. The species on the terrace have a higher surface diffusion compared to the species on the step allowing them to move toward the steps to nucleate. ${ }^{42,43} \mathrm{X}$-ray photoelectron spectroscopy (XPS) of the film deposited on $4 \mathrm{H}-\mathrm{SiC}$ at 325 ${ }^{\circ} \mathrm{C}$ with $5 \mathrm{~s}$ pulse of 1 and $9 \mathrm{~s} \mathrm{NH}_{3}$ plasma pulse showed 48.7 \pm 2.4 at. $\% \mathrm{In}, 48.6 \pm 2.4$ at. $\% \mathrm{~N}, 2.7 \pm 0.1$ at. $\% \mathrm{O}$ and no detectable C (Figure S12). The same amount of oxygen is bonded to In and $\mathrm{N}$, giving perfect $\mathrm{In} / \mathrm{N}$ ratio of 1.0. It should be noted that the InN film was capped with approximately 10 $\mathrm{nm}$ of AlN to avoid post deposition oxidation of the $\mathrm{InN}$ film. As preferential sputtering of $\mathrm{InN}$ can occur, this was minimized by applying the lowest sputtering energy and no tilting of the sample according to previously reported protocols. ${ }^{44}$ The high- 
a)

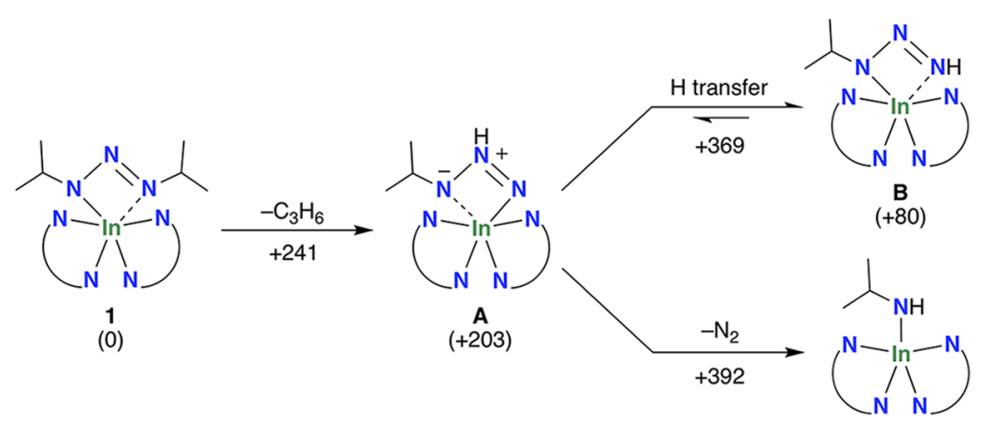

b)

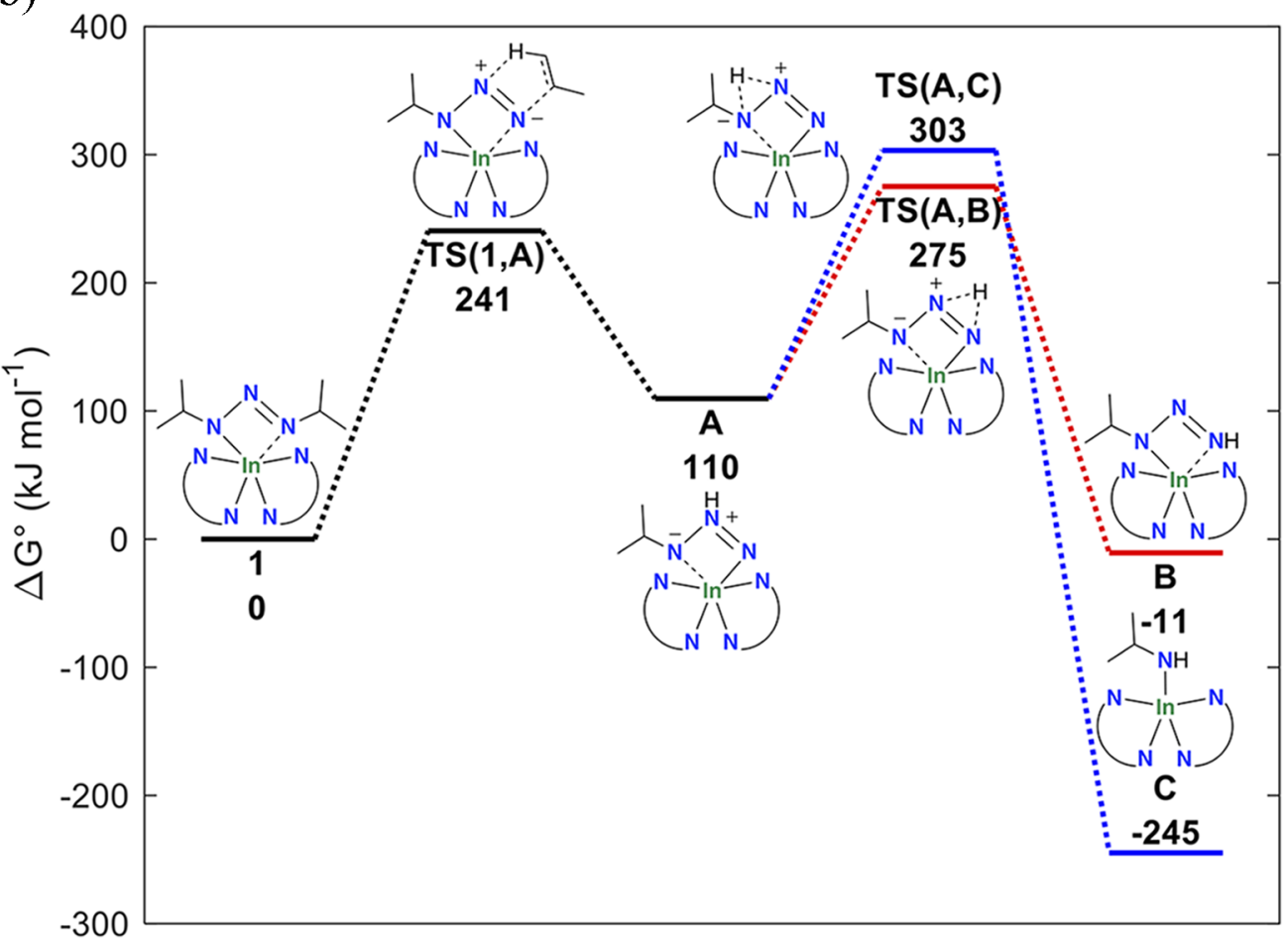

Figure 5. (a) DFT calculated decomposition pathways for the thermal decomposition of 1 at $300{ }^{\circ} \mathrm{C}$. The change in enthalpy is shown in each step and is given in $\mathrm{kJ} \mathrm{mol}^{-1}$. (b) Free energy profile for the decomposition of 1 at $300{ }^{\circ} \mathrm{C}$. The free energies are marked for each pathway and are given in $\mathrm{kJ} \mathrm{mol}^{-1}$.

resolution XPS of In $3 \mathrm{~d}_{5 / 2}$ and $\mathrm{N} 1 \mathrm{~s}$ was fitted with two subpeaks each. For In $3 d_{5 / 2}$, the major contribution at 444.6 $\mathrm{eV}$ was assigned to the $\mathrm{In}-\mathrm{N}$ bond, with a minor contribution at $445.7 \mathrm{eV}$ assigned to the $\mathrm{In}-\mathrm{O}$ bond. For the $\mathrm{N} 1 \mathrm{~s}$, the major contribution at $396.5 \mathrm{eV}$ was assigned to the $\mathrm{N}-\mathrm{In}$ bond, with a minor contribution at $397.6 \mathrm{eV}$ assigned to the $\mathrm{N}-\mathrm{O}$ bond. ${ }^{45-47}$ Raman spectroscopy of the InN films on $4 \mathrm{H}-$ $\mathrm{SiC}$ deposited at $325{ }^{\circ} \mathrm{C}$ (Figure $6 \mathrm{~d}$ ) shows the $\mathrm{A}_{1}(\mathrm{LO})$ band of wurtzite InN at approximately $573 \mathrm{~cm}^{-1}$, which agrees well with previously reported Raman shift ${ }^{48}$ and indicates low stress in the film. A very small shoulder was observed at $375 \mathrm{~cm}^{-1}$, which is a gap mode previously shown to correspond to In vacancies in $\mathrm{InN}^{48}$ The appearance of this gap mode is attributed to the small amount of oxygen in the film. The sheet resistance of $50 \mathrm{~nm} \mathrm{InN} \mathrm{films} \mathrm{is} \mathrm{on} \mathrm{average} 920 \Omega / \mathrm{sq}$, which corresponds to a resistivity of $0.46 \Omega \mathrm{cm}$. This value is comparable to previously reported InN deposited by ALD at $240{ }^{\circ} \mathrm{C}$. ${ }^{8}$ We could not determine the carrier concentration and the carrier mobility with high accuracy due to the limitations of the instrument used. The fitted electron mobility values are $10-500 \mathrm{~cm}^{2} /(\mathrm{V} \mathrm{s})$ depending on its correlated carrier concentration. We believe that this scattering is due to the confidence level of the fitting. Assuming a carrier concentration of $1 \times 10^{20} \mathrm{~cm}^{-3}$, the mobility is approximately $13 \mathrm{~cm}^{2} /(\mathrm{V} \mathrm{s})$. This value is in the same range as previously reported for InN films from ALD deposited at somewhat lower temperature. $^{8}$

\section{CONCLUSIONS}

In conclusion, we have developed a new highly volatile In(III) precursor and shown for the first time the use of a homoleptic triazenide in a vapor deposition process. This compound was easily synthesized using cheap and easily obtainable reagents. Thermogravimetric analysis showed that $\mathbf{1}$ underwent single step volatilization between 145 and $215{ }^{\circ} \mathrm{C}$ with negligible mass remaining, and heating studies showed it started to slowly decomposed at $\sim 200{ }^{\circ} \mathrm{C}$. Interestingly, 1 undergoes decomposition in the gas-phase at higher deposition temperatures to give a more reactive $\operatorname{In}($ III) compound that still 


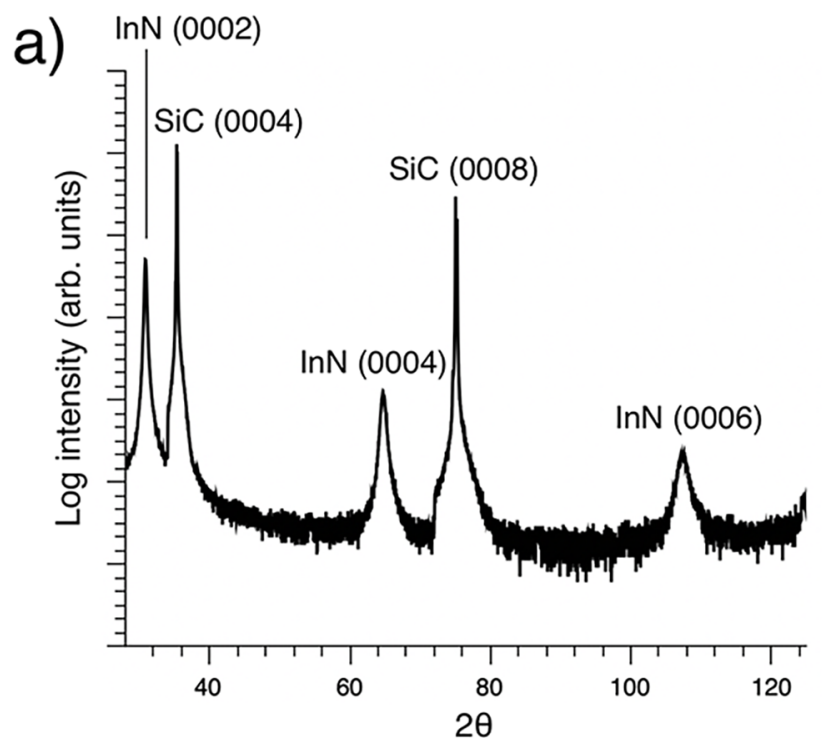

b)
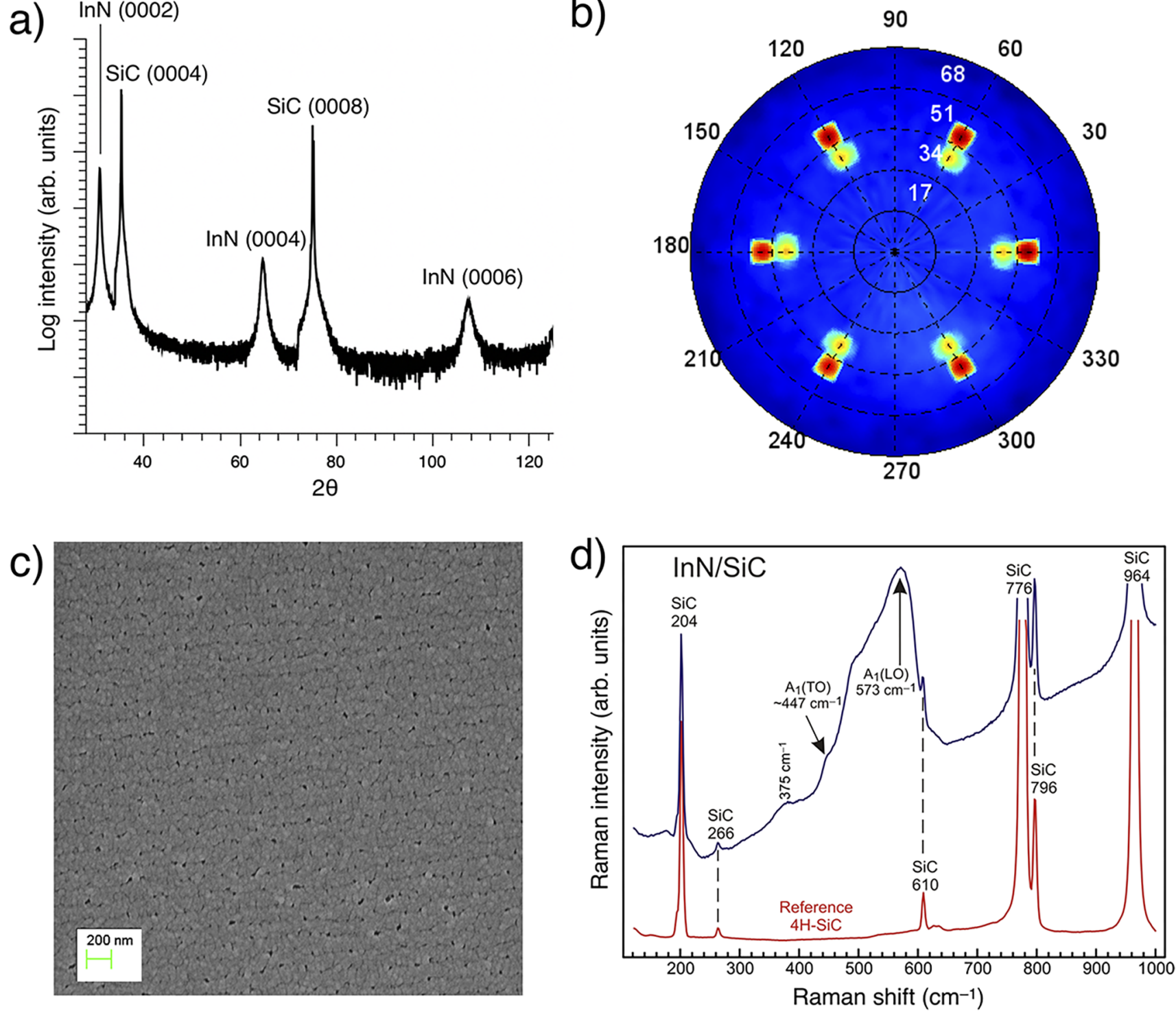

Figure 6. (a) $\mathrm{XRD}$ of $\mathrm{InN}$ on $4 \mathrm{H}-\mathrm{SiC}(0001)$ using a $5 \mathrm{~s}$ pulse of 1 and $9 \mathrm{~s} \mathrm{NH}_{3}$ plasma pulse deposited at $325^{\circ} \mathrm{C}$ showing epitaxial $\mathrm{InN}$ along the $c$-axis. (b) Pole figure of the $\operatorname{InN}(10-12)$ plane showing 12 poles, the outer 6 red poles corresponding to SiC and the inner 6 green/yellow poles to InN. (c) Top view SEM of InN on $4 \mathrm{H}-\mathrm{SiC}$ deposited at $325^{\circ} \mathrm{C}$. (d) Raman spectrum of $\mathrm{InN}$ on $4 \mathrm{H}$-SiC deposited at $325^{\circ} \mathrm{C}$ together with the reference spectrum of the substrate provided for comparison. The lines belonging to the $\mathrm{SiC}$ substrate are labeled "SiC" with their corresponding Raman shifts in $\mathrm{cm}^{-1}$.

possesses self-limiting behavior and without unwanted impurities in the film. DFT calculations showed that 1 decomposes to a smaller tricoordinated In(III) compound by liberating three molecules of propene and $\mathrm{N}_{2}$, and explains the increased growth rate observed in the higher temperature interval. This result has the potential to open a new path in ligand and precursor design for vapor deposition with deliberate gas-phase decomposition. ALD of InN using 1 and $\mathrm{NH}_{3}$ plasma afforded epitaxial $\mathrm{InN}$ on $4 \mathrm{H}-\mathrm{SiC}$ that was stoichiometric and with a very low level of impurities. Initial electrical characterization of the InN films shows a sheet resistivity of $920 \Omega /$ sq and electron mobility on par with the reported literature. This new triazenide ligand has potential to unlock ALD of InN for semiconductor applications and develop a new class of $\mathrm{M}-\mathrm{N}$ bonded precursors for future ALD processes.

\section{EXPERIMENTAL SECTION}

4.1. General Experimental Procedures. Caution! As catenated nitrogen compounds are known to be associated with explosive hazards, isopropylazide and compound $\mathbf{1}$ are possible explosive energetic materials. Although we have not experienced any problems in the synthesis, characterization, sublimation, and handling of compound 1, its energetic properties have not been investigated and are therefore unknown. We therefore highly recommend all appropriate standard safety precautions for handling explosive materials (safety glasses, face shield, blast shield, leather gloves, polymer apron, and ear protection) be used at all times when working with isopropylazide and compound 1 . All reactions and manipulations were carried out under an $\mathrm{N}_{2}$ atmosphere; on a Schlenk line using Schlenk air-free techniques and in a GS GloveboxSystemtechnik glovebox. All anhydrous solvents were purchased from Sigma-Aldrich and further dried with $4 \AA$ molecular sieves. $\mathrm{InCl}_{3}$ (98\%) and isopropyllithium solution were purchased from SigmaAldrich and both used without further purification. Isopropylazide was synthesized according to the literature procedure. ${ }^{40}$ All NMR spectra 
were measured with an Oxford Varian $300 \mathrm{MHz}$ spectrometer. The $\mathrm{C}_{6} \mathrm{D}_{6}$ solvent peaks were used as an internal standard for the ${ }^{1} \mathrm{H}$ NMR $(300 \mathrm{MHz})$ and ${ }^{13} \mathrm{C}\left\{{ }^{1} \mathrm{H}\right\}$ NMR $(75 \mathrm{MHz})$ spectra. The electrospray ionization (ESI)-MS data was obtained on a Thermo Scientific LCQ Fleet ESI-MS instrument. The melting point was determined in a capillary sealed under $\mathrm{N}_{2}$ with a Stuart SMP10 melting point apparatus and is uncorrected. Elemental analysis was performed by Mikroanalytisches Laboratorium Kolbe, Germany.

4.2. Synthesis of Tris(1,3-diisopropyltriazenide)indium(III) (1). To a solution of isopropylazide ${ }^{40}(5.90 \mathrm{~g}, 69.3 \mathrm{mmol})$ in $\mathrm{Et}_{2} \mathrm{O}$ $(100 \mathrm{~mL})$ at $-78{ }^{\circ} \mathrm{C}$ was added isopropyllithium $(0.7 \mathrm{M}$ in pentane, $99.0 \mathrm{~mL}, 69.3 \mathrm{mmol}$ ). The reaction mixture was stirred for $30 \mathrm{~min}$ and then allowed to warm up to room temperature for $1 \mathrm{~h}$. This solution was then added to a $-78{ }^{\circ} \mathrm{C}$ solution of $\operatorname{InCl}_{3}(5.11 \mathrm{~g}, 23.1$ $\mathrm{mmol})$ in THF $(100 \mathrm{~mL})$ via cannula and the mixture was stirred at this temperature for $20 \mathrm{~min}$. The reaction was warmed to room temperature and stirred for $16 \mathrm{~h}$. The reaction mixture was concentrated under reduced pressure, and the resulting residue was dissolved in $n$-hexanes, filtered through a pad of Celite, and concentrated under reduced pressure to give a light-yellow solid. The solid was purified by sublimation at $80{ }^{\circ} \mathrm{C}(0.5 \mathrm{mbar})$ to give compound 1 as a solid (8.19 g, 71\%).

1: Colorless solid, decomp. $212-214{ }^{\circ} \mathrm{C} .{ }^{1} \mathrm{H}$ NMR $(300 \mathrm{MHz}$, $\left.\mathrm{C}_{6} \mathrm{D}_{6}\right) \delta 1.23\left(\mathrm{~d}, J=6.0 \mathrm{~Hz}, 36 \mathrm{H}, \mathrm{CH}_{3}\right), 4.06(\mathrm{sept}, J=6.0 \mathrm{~Hz}, 6 \mathrm{H}$, $\mathrm{CH}) .{ }^{13} \mathrm{C}\left\{{ }^{1} \mathrm{H}\right\}$ NMR $\left(75 \mathrm{MHz}, \mathrm{C}_{6} \mathrm{D}_{6}\right) \delta 24.0\left(\mathrm{~s}, \mathrm{CH}_{3}\right), 53.7(\mathrm{~s}, \mathrm{CH})$. LRMS (ESI, positive) $\mathrm{m} / z=500[\mathrm{M}+\mathrm{H}]^{+}$. Anal. calcd. for $\mathrm{C}_{18} \mathrm{H}_{42} \mathrm{InN}_{9}$ : C, $43.29 \%$; H, 8.48\%; N, 25.24\%. Found: C, $42.64 \%$; $\mathrm{H}$, $8.25 \% ; \mathrm{N}, 24.90 \%$.

4.3. X-ray Crystallographic Analysis. Colorless single crystals were obtained by recrystallization from $n$-hexanes at $-35{ }^{\circ} \mathrm{C}$ for $\mathbf{1}$. The single crystals were used for X-ray diffraction data collection on a Bruker D8 SMART Apex-II diffractometer using graphite-monochromated $\mathrm{Mo}-\mathrm{K} \alpha$ radiation $(\lambda=0.71073 \AA)$. All data were collected in hemisphere with over $95 \%$ completeness to $2 \theta<50.05^{\circ}$. The structures were solved by direct methods. The coordinates of metal atoms were determined from the initial solutions, and of the $\mathrm{N}$ and $\mathrm{C}$ methods, located in subsequent differential Fourier syntheses. All non-hydrogen atoms were refined first in isotropic and then in anisotropic approximation using Bruker SHELXTL software. Additional crystal data are available at the Cambridge Crystallographic Data Centre, deposition no. CCDC 1966432.

4.4. Thermogravimetric Analysis. Volatilization and vapor pressure curves were collected using a TA Instruments thermogravimetric analysis Q500 tool inside an $\mathrm{N}_{2}$ filled glovebox. The ramp experiment of 1 was undertaken in tared platinum pans loaded with 6 $\mathrm{mg}$ and $17 \mathrm{mg}$ of $\mathbf{1}$ for low and high mass volatilization experiments, respectively. The furnace was heated at a rate of $10{ }^{\circ} \mathrm{C} / \mathrm{min}$ to $500{ }^{\circ} \mathrm{C}$ with a maintained $\mathrm{N}_{2}$ flow rate of $60 \mathrm{sccm}$.

4.5. Differential Scanning Calorimetry Analysis. The DSC measurement for $\mathbf{1}$ was performed on a TA Instruments DSC Q10 tool. A sample of $\sim 0.2 \mathrm{mg}$ of $\mathbf{1}$ was prepared in a sealed aluminum pan in an $\mathrm{N}_{2}$ filled glovebox. The sample of $\mathbf{1}$ and a blank reference pan was heated at a rate of $10{ }^{\circ} \mathrm{C} / \mathrm{min}$ to $400{ }^{\circ} \mathrm{C}$.

4.6. Quantum-Chemical Computations. All quantum chemical computations were preformed using Gaussian 16 software. $^{49}$ Structural optimization and harmonic normal mode vibrational calculations were undertaken using the hybrid DFT method $\mathrm{B} \mathrm{LYP}^{50,51}$ together with Grimme's version 3 dispersion correction ${ }^{52}$ and def2TZVP ${ }^{53,54}$ basis set. The decomposition path was investigated by searching for possible stable structures as well as finding transition states connecting these structures. Minima were confirmed to have no imaginary frequencies, while transition states were verified to have one imaginary frequency, lying along the reaction path.

4.7. Film Deposition. A hot-wall Picosun R-200 was used for the deposition of InN, which was equipped with a Litmas remote plasma source. The tool operated at 4 mbar with a continuous flow of high purity $\mathrm{N}_{2}$ (99.999\%) into the chamber, which was also used as the purge gas. The system was equipped with a traditional stainless-steel precursor container (bubbler), albeit without dip-tube for the incoming carrier gas. The system was baked at $450{ }^{\circ} \mathrm{C}$ for $2 \mathrm{~h}$ with a $300 \mathrm{sccm}$ flow of $\mathrm{N}_{2}$ to remove traces of $\mathrm{H}_{2} \mathrm{O}$ and $\mathrm{O}_{2}$ in the deposition chamber after exposure to the atmosphere during substrate exchange. In an $\mathrm{N}_{2}$ filled glovebox, $\sim 300 \mathrm{mg}$ of 1 was weighed into a glass vial, which was placed in a stainless-steel container and assembled onto the ALD tool. Caution! The bubbler must not be overfilled with multigram scale of precursor 1 due to possible explosion risk. The optimal temperature for the bubbler to obtain a high enough vapor pressure to saturate the substrate surface and obtain optimal growth was $125^{\circ} \mathrm{C}$. An amount of $\sim 300 \mathrm{mg}$ of precursor was enough for 500 cycles, and increased linearly with the number of cycles. $\mathrm{NH}_{3}$ plasma was used as the nitrogen source, containing a 100/75 $\mathrm{sccm}$ $\mathrm{Ar} / \mathrm{NH}_{3}$ gas mixture with a $2800 \mathrm{~W}$ plasma power and was located approximately $75 \mathrm{~cm}$ above the substrate. ${ }^{10}$ Unless otherwise stated, a $9 \mathrm{~s} \mathrm{NH}_{3}$ pulse was used followed by a $10 \mathrm{~s}$ purge. The $\mathrm{Si}(100)$ and $4 \mathrm{H}-\mathrm{SiC}$ substrates were cut into $15 \times 15 \mathrm{~mm}^{2}$ pieces, and films were deposited onto them without any further ex situ cleaning. Prior to deposition, a $120 \mathrm{~s}$ pulse of $\mathrm{H}_{2}$ plasma $\left(1000 \mathrm{~W}\right.$, gas mixture of $\mathrm{Ar} / \mathrm{H}_{2}$ $100 / 10 \mathrm{sccm}$ ) and $\mathrm{N}_{2}$ plasma (2800 W, gas mixture of $\mathrm{Ar} / \mathrm{N}_{2} 80 / 380$ $\mathrm{sccm}$ ) was employed to nitridize the substrate surface and to remove residual $\mathrm{H}_{2} \mathrm{O}$ and $\mathrm{O}_{2}$ from inside the deposition chamber.

4.8. Film Characterization. Film thickness and film crystallinity $(\theta-2 \theta)$ were measured with X-ray reflectivity (XRR), PANalytical X'Pert PRO with a $\mathrm{Cu}$-anode tube and Bragg-Brentano HD optics. To analyze the thickness, the software PANalytical X'Pert reflectivity and a two-layer model was used to fit the data, $\mathrm{InN} /$ substrate. PANalytical EMPYREAN MRD XRD with a Cu-anode X-ray tube and 5-axis (x-y-z-v-u) sample stage operating at $45 \mathrm{kV}$ and $40 \mathrm{~mA}$ was used in GIXRD mode with $0.5^{\circ}$ incident angle to analyze the crystallinity of the films. The pole figures were obtained with the same $\mathrm{XRD}$ equipment and operating parameters using an X-ray lens and parallel plate collimator. The morphology of the films was examined with a LEO 1550 SEM operating at an acceleration energy of $10 \mathrm{kV}$. Kratos AXIS Ultra DLD XPS was used to analyze the composition and the chemical environment of the atoms in the film. The XPS tool was equipped with an Ar sputtering source $(0.5 \mathrm{keV})$, which was used for clean sputtering and depth profiling of the films. To analyze the data, CasaXPS was used. The high-resolution scans were fitted by Gaussian-Laurentius functions and Shirley background. Raman spectra were recorded on a micro-Raman setup utilizing $100 \times$ objective and $532 \mathrm{~nm}$ solid-state laser (Coherent, Sapphire SF 532150 ). The laser was focused to a $\sim 0.8 \mu \mathrm{m}$ spot on the sample and a power below $1 \mathrm{~mW}$ was used to avoid overheating. The Raman signal was dispersed by a monochromator (Jobin Yvon, HR460) coupled to a CCD camera. With the 600 grooves $/ \mathrm{mm}$ grating used in this measurement, the resolution was about $5.5 \mathrm{~cm}^{-1}$. To obtain high signal-to-noise ratio, 100 subsequent acquisitions of $10 \mathrm{~s}$ were obtained for each sample resulting in a total acquisition time of 1000 s. No changes were observed in the spectra during the series, indicating that the laser power utilized was sufficiently low to avoid thermal damage.

\section{ASSOCIATED CONTENT}

\section{st Supporting Information}

The Supporting Information is available free of charge at https://pubs.acs.org/doi/10.1021/acs.chemmater.9b05171.

Precursor and film characterization, and computational calculations data (PDF)

Crystallographic data (CIF)

\section{AUTHOR INFORMATION}

\section{Corresponding Author}

Nathan J. O'Brien - Department of Physics, Chemistry and Biology, Linköping University, Linköping SE-58183, Sweden; ○ orcid.org/0000-0003-3633-9674; Email: nathan.o.brien@ liu.se 


\section{Authors}

Polla Rouf - Department of Physics, Chemistry and Biology, Linköping University, Linköping SE-58183, Sweden; (1) orcid.org/0000-0002-1452-4548

Rouzbeh Samii - Department of Physics, Chemistry and Biology, Linköping University, Linköping SE-58183, Sweden

Karl Rönnby - Department of Physics, Chemistry and Biology, Linköping University, Linköping SE-58183, Sweden; (1) orcid.org/0000-0002-8066-9454

Sydney C. Buttera - Department of Chemistry, Carleton University, Ottawa, Ontario K1S 5B6, Canada

Chih-Wei Hsu - Department of Physics, Chemistry and Biology, Linköping University, Linköping SE-58183, Sweden

Ivan G. Ivanov - Department of Physics, Chemistry and Biology, Linköping University, Linköping SE-58183, Sweden

Vadim Kessler - Department of Molecular Sciences, Swedish University of Agricultural Sciences, 75007 Uppsala, Sweden

Lars Ojamäe - Department of Physics, Chemistry and Biology, Linköping University, Linköping SE-58183, Sweden; (1) orcid.org/0000-0002-5341-2637

Henrik Pedersen - Department of Physics, Chemistry and Biology, Linköping University, Linköping SE-58183, Sweden; () orcid.org/0000-0002-7171-5383

Complete contact information is available at:

https://pubs.acs.org/10.1021/acs.chemmater.9b05171

\section{Notes}

The authors declare no competing financial interest.

\section{ACKNOWLEDGMENTS}

The authors acknowledge Laurent Souqui for the assistance with the pole figure measurements and Seán Barry for access to TGA and DSC instruments. This project was founded by the Swedish foundation for Strategic Research through the project "Time-resolved low temperature CVD for III-nitrides" (SSFRMA 15-0018) and by the Knut and Alice Wallenberg foundation through the project "Bridging the THz gap" (No. KAW 2013.0049). L.O. acknowledges financial support from the Swedish Government Strategic Research Area in Materials Science on Functional Materials at Linköping University (Faculty Grant SFO Mat LiU No. 2009 00971). Supercomputing resources were provided by the Swedish National Infrastructure for Computing (SNIC) and the Swedish National Supercomputer Centre (NSC).

\section{REFERENCES}

(1) Bhuiyan, A. G.; Hashimoto, A.; Yamamoto, A. Indium Nitride (InN): A Review on Growth, Characterization and Properties. J. Appl. Phys. 2003, 94, 2779-2808.

(2) Butcher, K. S. A.; Tansley, T. L. Latest Development and a Review of the Band-Gap Controversy. Superlattices Microstruct. 2005, $38,1-37$.

(3) Zhang, B. L.; Sun, G. S.; Guo, Y.; Zhang, P. F.; Zhang, R. Q.; Fan, H. B.; Liu, X. L.; Yang, S. Y.; Zhu, Q. S.; Wang, Z. G. Valence band offset of $\mathrm{InN} / 4 \mathrm{H}-\mathrm{SiC}$ heterojunction measured by x-ray photoelectron spectroscopy. Appl. Phys. Lett. 2008, 93, 242107.

(4) Ivanov, S. V.; Shubina, T. V.; Komissarova, T. A.; Jmerik, V. N. Metastable Nature of InN and In-Rich InGaN Alloys. J. Cryst. Growth 2014, 403, 83-89.

(5) Ruffenach, S.; Moret, M.; Briot, O.; Gil, B. Recent Advances in the MOVPE Growth of Indium Nitride. Phys. Status Solidi A 2010, 1, $9-18$.

(6) Zhou, J.; Huang, Q.; Li, J.; Cai, D.; Kang, J. The InN Epitaxy via Controlling In Bilayer. Nanoscale Res. Lett. 2014, 9, 5.
(7) George, S. M. Atomic Layer Deposition: An Overview. Chem. Rev. 2010, 110, 111-131.

(8) Nepal, N.; Mahadik, N. A.; Nyakiti, L. O.; Qadri, S. B.; Mehl, M. J.; Hite, J. K.; Eddy, C. R. J. Epitaxial Growth of Cubic and Hexagonal InN Thin Films via Plasma-Assisted Atomic Layer Epitaxy. Cryst. Growth Des. 2013, 13, 1485-1490.

(9) Haider, A.; Kizir, S.; Biyikli, N. Low-Temperature Self-Limiting Atomic Layer Deposition of Wurtzite $\mathrm{InN}$ on $\mathrm{Si}(100)$. AIP Adv. 2016, 6, 045203 .

(10) Deminskyi, P.; Rouf, P.; Ivanov, I. G.; Pedersen, H. Atomic Layer Deposition of InN Using Trimethylindium and Ammonia Plasma. J. Vac. Sci. Technol., A 2019, 37, 020926.

(11) Wakahara, A.; Tsuchiya, T.; Yoshida, A. Epitaxial Growth of Indium Nitride. J. Cryst. Growth 1990, 99, 385-389.

(12) Feng, X.; Peng, H.; Gong, J.; Wang, W.; Liu, H.; Quan, Z.; Pan, S.; Wang, L. Epitaxial Growth of InN Thin Films by Plasma-Enhanced Atomic Layer Deposition. J. Appl. Phys. 2018, 124, 243104.

(13) Bürger, H.; Cichon, J.; Goetze, U.; Wannagat, U.; Wismar, H. Beiträgezur Chemie Der Silicium-Stickstoff-Verbindungen: CVII. Darstellung, Schwingungsspektren Und Normalkoordinatenanalyse von Disilylamiden Der 3. Gruppe: $\mathrm{M}\left[\mathrm{N}\left(\mathrm{SiMe}_{3}\right)_{2}\right]_{3}$ Mit $\mathrm{M}=\mathrm{Al}$, Ga Und In. J. Organomet. Chem. 1971, 33, 1-12.

(14) Rossetto, G.; Brianese, N.; Camporese, A.; Porchia, M.; Zanella, P.; Bertoncello, R. Synthesis and Charaeterization of Hexakis(Diethylamido)Diindium(III) and Bis-Cyclopentadienyl(Diethylamido)Indium(III). Main Gr. Met. Chem. 1991, 14, 113-122.

(15) Petrie, M. A.; Ruhlandt-Senge, K.; Hope, H.; Power, P. P. Structural Studies of the Monomeric, Low Coordinate, Indium Amides $(\mathrm{t}-\mathrm{Bu})_{2} \operatorname{InN}\left(2,6-i-\mathrm{Pr}_{2} \mathrm{C}_{6} \mathrm{H}_{3}\right) \mathrm{SiPh}_{3}$ and $\operatorname{In}\left\{\mathrm{N}\left(\mathrm{SiMe}_{3}\right)_{2}\right\}_{3}$. Bull. Soc. Chim. Fr. 1993, 130, 851-855.

(16) Frey, R.; Gupta, V. D.; Linti, G. Monomere Bis- Und Tris(Amide) Des Indiums. Z. Anorg. Allg. Chem. 1996, 622, 10601064.

(17) Kim, J.; Bott, S. G.; Hoffman, D. M. Synthesis of Indium Amide Compounds. Inorg. Chem. 1998, 37, 3835-3841.

(18) Gebhard, M.; Hellwig, M.; Kroll, A.; Rogalla, D.; Winter, M.; Mallick, B.; Ludwig, A.; Wiesing, M.; Wieck, A. D.; Grundmeir, G.; et al. New Amidinate Complexes of Indium(III): Promising CVD Precursor for Transparent and Conductive $\operatorname{In}_{2} \mathrm{O}_{3}$ Thin Films. Dalt. Trans. 2017, 46, 10220-10231.

(19) Kim, S. B.; Jayaraman, A.; Chua, D.; Davis, L. M.; Zheng, S.-L.; Zhao, X.; Lee, S.; Gordon, R. G. Obtaining a Low and Wide Atomic Layer Deposition Window $\left(150-275{ }^{\circ} \mathrm{C}\right)$ for $\operatorname{In}_{2} \mathrm{O}_{3}$ Films Using an InIII Amidinate and $\mathrm{H}_{2} \mathrm{O}$. Chem. - Eur. J. 2018, 24, 9525-9529.

(20) Barry, S. T.; Gordon, P. G.; Ward, M. J.; Heikkila, M. J.; Monillas, W. H.; Yap, G. P. A.; Ritala, M.; Leskelä, M. Chemical Vapour Deposition of In2O3 Thin Films from a Tris-Guanidinate Indium Precursor. Dalt. Trans. 2011, 40, 9425-9430.

(21) Gebhard, M.; Hellwig, M.; Parala, H.; Xu, K.; Winter, M.; Devi, A. Indium-Tris-Guanidinates: A Promising Class of Precursors for Water Assisted Atomic Layer Deposition of $\mathrm{In}_{2} \mathrm{O}_{3}$ Thin Films. Dalt. Trans. 2014, 43, 937-940.

(22) McCarthy, R. F.; Weimer, M. S.; Emery, J. D.; Hock, A. S.; Martinson, A. B. F. Oxygen-Free Atomic Layer Deposition of Indium Sulfide. ACS Appl. Mater. Interfaces 2014, 6, 12137-12145.

(23) Rouf, P.; O’Brien, N. J.; Rönnby, K.; Samii, R.; Ivanov, I. G.; Ojamäe, L.; Pedersen, H. The Endocyclic Carbon Substituent of Guanidinate and Amidinate Precursors Controlling ALD of InN Films. J. Phys. Chem. C 2019, 123, 25691-25700.

(24) Gantzel, P.; Walsh, P. J. Synthesis and Crystal Structures of Lithium and Potassium Triazenide Complexes. Inorg. Chem. 1998, 37, $3450-3451$

(25) Nimitsiriwat, N.; Gibson, V. C.; Marshall, E. L.; Takolpuckdee, P.; Tomov, A. K.; White, A. J. P.; Williams, D. J.; Elsegood, M. R.; Dale, S. H. Mono- versus Bis-Chelate Formation in Triazenide and Amidinate Complexes of Magnesium and Zinc. Inorg. Chem. 2007, 46, 9988-9997.

(26) Dwyer, F. P. Chelation in Metallic Triazene Salts. J. Am. Chem. Soc. 1941, 63, 78-81. 
(27) Corbett, M.; Hoskins, B. F. The Structure of Monoclinic Tris(1,3-Diphenyltriazenato)Cobalt(III)- Toluene (1/1): An Octahedral Complex Containing Three Four-Membered Chelate Rings. Aust. J. Chem. 1974, 27, 665-670.

(28) Black, D. S. C.; Davis, V. C.; Deacon, G. B.; Schultze, R. J. Tris(Triazenido)Thallium(III) Compounds. Inorg. Chim. Acta 1979, 37, L528.

(29) Guzei, I. A.; Liable-Sands, L. M.; Rheingold, A. L.; Winter, C. $\mathrm{H}$. Synthesis and Characterization of Titanium and Zirconium Complexes Bearing Diphenyltriazenido Ligands. Polyhedron 1997, 16, 4017-4022.

(30) Ríos-Moreno, G.; Aguirre, G.; Parra-Hake, M.; Walsh, P. J. Synthesis, Characterization, and Structure of Dinuclear Copper(I) and Silver(I) Complexes of Ortho-Functionalized 1,3-Bis(Aryl)Triazenide Ligands. Polyhedron 2003, 22, 563.

(31) Johnson, A. L.; Willcocks, A. M.; Richards, S. P. Synthesis and Structures of Group 11 Metal Triazenide Complexes: Ligand Supported Metallophilic Interactions. Inorg. Chem. 2009, 48, 86138622.

(32) Lee, H. S.; Niemeyer, M. Homoleptic Heavy Alkaline Earth and Europium Triazenides. Inorg. Chem. 2010, 49, 730-735.

(33) Hinz, A.; Schulz, A.; Villinger, A.; Wolter, J.-W. Cyclo-PnictaTriazanes: Biradicaloids or Zwitterions? J. Am. Chem. Soc. 2015, 137, $3975-3980$.

(34) Flanagan, K. R.; Parish, J. D.; Fox, M. A.; Johnson, A. L. Synthetic, Structural, and Computational Studies on Heavier Tetragen and Chalcogen Triazenide Complexes. Inorg. Chem. 2019, $58,16660-16666$.

(35) Leman, J. T.; Barron, A. R.; et al. Synthesis of 1,3Diphenyltriazenide Complexes of Aluminium, Gallium and Indium: Crystal Structure of Tris(1,3-Diphenyltriazenido)Aluminium(III). Polyhedron 1989, 8, 1909-1912.

(36) Leman, J. T.; Roman, H. A.; Barron, A. R. Five- and SixCoordinate Organometallic Compounds of Indium. Organometallics 1993, 12, 2986-2990.

(37) Brinckman, F. E.; Haiss, H. S.; Robb, R. A. Metal-Nitrogen Bonding. Covalent Complexes of 1,3-Dimethyltriazene with Elements of Groups I, II, III, IV, and V. Inorg. Chem. 1965, 4, 936-942.

(38) Soussi, K.; Mishra, S.; Jeanneau, E.; Millet, J.-M.; Daniele, S. Asymmetrically Substituted Triazenes as Poor Electron Donor Ligands in the Precursor Chemistry of Iron(II) for Iron-Based Metallic and Intermetallic Nanocrystals. Dalt. Trans. 2017, 46, 13055-13064.

(39) Soussi, K.; Mishra, S.; Jeanneau, E.; Mantoux, A.; Stéphane, D. Synthesis, Characterization and Thermal Transport Properties of Heteroleptic N-alkyltriazenide Complexes of Titanium(IV) and Niobium(V). Polyhedron 2018, 152, 84-89.

(40) Swetha, M.; Venkata Ramana, P.; Shirodkar, S. G. Simple and Efficient Method for the Synthesis of Azides in Water-THF Solvent System. Org. Prep. Proced. Int. 2011, 43, 348-353.

(41) Barry, S. T. Amidinates, Guanidinates and Iminopyrrolidinates: Understanding Precursor Thermolysis to Design a Better Ligand. Coord. Chem. Rev. 2013, 257, 3192-3201.

(42) Rubel, O.; Baranovskii, S. D. Formation Energies of Antiphase Boundaries in GaAs and GaP: An Ab Initio Study. Int. J. Mol. Sci. 2009, 10, 5104-5114.

(43) Starr, D. E.; Campbell, C. T. Large Entropy Difference between Terrace and Step Sites on Surfaces. J. Am. Chem. Soc. 2008, 130, $7321-7327$

(44) Krischok, S.; Yanev, V.; Balykov, O.; Himmerlich, M.; Schaefer, J. A.; Kosiba, R.; Ecke, G.; Cimalla, I.; Cimalla, V.; Ambacher, O.; et al. Investigations of MBE Grown InN and the Influence of Sputtering on the Surface Composition. Surf. Sci. 2004, 566-568, 849-855.

(45) Veal, T. D.; King, P. D. C.; Jefferson, P. H.; Piper, L. F. J.; McConville, C. F.; Lu, H.; Schaff, W. J.; Anderson, P. A.; Durbin, S. M.; Muto, D.; et al. In Adlayers on C-Plane InN Surfaces: A PolarityDependent Study by x-Ray Photoemission Spectroscopy. Phys. Rev. B: Condens. Matter Mater. Phys. 2007, 76, 075313.
(46) Wu, C. L.; Lee, H. M.; Kuo, C. T.; Chen, C. H.; Gwo, S. Absence of Fermi-Level Pinning at Cleaved Nonpolar InN Surfaces. Phys. Rev. Lett. 2008, 76, 075313.

(47) Nagata, T.; Koblmüller, G.; Bierwagen, O.; Gallinat, C. S.; Speck, J. S. Surface Structure and Chemical States of A-Plane and cPlane InN Films. Appl. Phys. Lett. 2009, 95, 132104.

(48) Wang, J. B.; Li, Z. F.; Chen, P. P.; Lu, W.; Yao, T. Raman Study of Gap Mode and Lattice Disorder Effect in InN Films Prepared by Plasma-Assisted Molecular Beam Epitaxy. Acta Mater. 2007, 55, 183187.

(49) Frisch, M. J.; Trucks, G. W.; Schlegel, H. B.; Scuseria, G. E.; Robb, M. A.; Cheeseman, J. R.; Scalmani, G.; Barone, V.; Mennucci, B.; Petersson, G. A.; Nakatsuji, H.; Caricato, M.; Li, X.; Hratchian, H. P.; Izmaylov, A. F.; Bloino, J.; Zheng, G.; Sonnenberg, J. L.; Hada, M.; Ehara, M.; Toyota, K.; Fukuda, R.; Hasegawa, J.; Ishida, M.; Nakajima, T.; Honda, Y.; Kitao, O.; Nakai, H.; Vreven, T.; Montgomery, J. A., Jr.; Peralta, J. E.; Ogliaro, F.; Bearpark, M.; Heyd, J. J.; Brothers, E.; Kudin, K. N.; Staroverov, V. N.; Kobayashi, R.; Normand, J.; Raghavachari, K.; Rendell, A.; Burant, J. C.; Iyengar, S. S.; Tomasi, J.; Cossi, M.; Rega, N.; Millam, J. M.; Klene, M.; Knox, J. E.; Cross, J. B.; Bakken, V.; Adamo, C.; Jaramillo, J.; Gomperts, R.; Stratmann, R. E.; Yazyev, O.; Austin, A. J.; Cammi, R.; Pomelli, C.; Ochterski, J. W.; Martin, R. L.; Morokuma, K.; Zakrzewski, V. G.; Voth, G. A.; Salvador, P.; Dannenberg, J. J.; Dapprich, S.; Daniels, A. D.; Farkas, O.; Foresman, J. B.; Ortiz, J. V.; Cioslowski, J.; Fox, D. J. Gaussian 16, revision B.01; Gaussian, Inc.: Wallingford, CT, 2016.

(50) Becke, A. D. Density-Functional Thermochemistry. III. The Role of Exact Exchange. J. Chem. Phys. 1993, 98, 5648-5652.

(51) Lee, C.; Yang, W.; Parr, R. G. Development of the ColleSalvetti Correlation-Energy Formula into a Functional of the Electron Density. Phys. Rev. B: Condens. Matter Mater. Phys. 1988, 37, 785789.

(52) Grimme, S.; Antony, J.; Ehrlich, S.; Krieg, H. A Consistent and Accurate Ab Initio Parametrization of Density Functional Dispersion Correction (DFT-D) for the 94 Elements H-Pu. J. Chem. Phys. 2010, 132 (15), 154104.

(53) Weigend, F.; Ahlrichs, R. Balanced Basis Sets of Split Valence, Triple Zeta Valence and Quadruple Zeta Valence Quality for H to Rn: Design and Assessment of Accuracy. Phys. Chem. Chem. Phys. 2005, 7, 3297-3305.

(54) Metz, B.; Stoll, H.; Dolg, M. Small-Core MulticonfigurationDirac-Hartree-Fock-Adjusted Pseudopotentials for Post-d Main Group Elements: Application to $\mathrm{PbH}$ and $\mathrm{PbO}$. J. Chem. Phys. 2000, 113, 2563-2569. 